Check for updates

Cite this: RSC Adv., 2017, 7, 37447

\title{
Tribological properties of lanthanum perrhenate as lubricating additive over a wide temperature range
}

\begin{abstract}
Junhai Wang, (D)*ab Lixiu Zhang, ${ }^{a}$ Ting $\mathrm{Li}^{a}{ }^{a}$ Ke Zhang ${ }^{a}$ and Bing $\mathrm{Lu}^{\mathrm{a}}$
Lanthanum perrhenate for use as a lubricating additive was prepared via the aqueous solution method in this study, and was dispersed into a pentaerythritol ester (PETE) base oil accompanied by surface active agents. The thermal stability of the complex oil with/without lanthanum perrhenate and surface active agents was evaluated by thermogravimetry. The influences of lanthanum perrhenate as a solid lubricating additive on the extreme pressure performance and friction-reducing property of the complex lubricants in a wide temperature range were investigated by four-ball tests and ball-on-disc frictional tests with a silicon nitride ball and $\mathrm{Ni}$-base superalloy frictional pair. The results suggested that the added lanthanum perrhenate did not significantly affect the thermal stability and anti-oxidation properties of PETE, and improved the extreme pressure performance of the base oil. Additionally, it decreased the friction coefficient and wear scar diameter to a certain degree. The complex oil had a similar lubricating performance to the base oil below the decomposition temperature point; within the scope of $350{ }^{\circ} \mathrm{C}$ to $600{ }^{\circ} \mathrm{C}$, the friction coefficients of oil containing the lanthanum perrhenate additive were markedly lower than that of the base oil, and this was attributed to lanthanum perrhenate's intrinsic shear susceptibility and resistance to phase transformation under high temperature conditions, enabling it to form an effective antifriction layer with native oxides of the superalloy matrix, thus reducing the friction

in high-temperature environments.
\end{abstract}

Received 27th May 2017

Accepted 17th July 2017

DOI: 10.1039/c7ra05953a

rsc.li/rsc-advances

\section{Introduction}

Designing and preparing continuous lubricating materials over a wide temperature range are challenges for high-technology industries. ${ }^{1-3}$ Oils and greases are known to volatilize or experience chemical degradation with increasing temperature. Conventional solid lubricants, such as graphite and molybdenum disulfide, are always oxidized above $400{ }^{\circ} \mathrm{C}$ in atmospheric conditions, such that their friction-reducing ability is impaired above that temperature. ${ }^{4}$ Although some inorganic materials are candidates for lubrication by virtue of their low shear strength at elevated temperatures, these compounds are brittle and non-lubricating at low temperatures. ${ }^{5,6}$ Any singlespecies lubricating material performs only within a narrow temperature range, which makes it difficult to satisfy the demand for continuous lubrication in a wide temperature range. ${ }^{7}$ Therefore, the combination of multiple lubricants is one effective way to realize continuous lubrication over a wide temperature range. At present, self-lubricating block materials and self-lubricating composite coatings are widely used as lubricants for wide temperature range applications. The added

${ }^{a}$ School of Mechanical Engineering, Shenyang Jianzhu University, No. 9 Hunnan East Road, Hunnan District, Shenyang 110168, China. E-mail: jhwang10b@alum.imr.ac. cn; Fax: +86 24 24694412; Tel: +862424694412

${ }^{b}$ Institute of Metal Research, Chinese Academy of Sciences, Shenyang 110016, China lubrication phase can improve the lubricating properties of block materials, and composite coatings not only promote the tribological characteristics of lubricants, but the different phases also restrain the grain growth of composite coatings, which in turn greatly increases the coating surface hardness and prevents micro-crack propagation within the coating. ${ }^{8-15}$ However, the excessive incorporation of lubrication phases will lead to deterioration of the mechanical properties of block materials; composite coatings, with a finite life span, encounter supply difficulties, and their failure can result in disastrous consequences. Although solid lubricants possess excellent antifriction behaviour at high temperatures, it is difficult for solid lubricants to achieve low friction at room temperature, unlike oil-based lubricants. Consequently, the development of solid/liquid hybrid lubrication modes has been explored for fulfilling a lubricating function over a wide temperature range. In addition, these modes offer a series of advantages, such as reliable supply, ease of handling and low cost. Qi et al. have researched the tribological behaviour of oils containing serpentine powder at high temperature, and found that many factors had an impact on the lubricating performances of the solid/liquid hybrid mode, such as temperature, oil oxidation and tribological chemical reactions. ${ }^{16}$ In principle, the ideal hybrid lubrication mode would achieve a smooth transition between lubrication states and enable efficient lubrication. This requires that the solid lubricant has desirable tribological 
properties at high temperature while retaining its softness and shear susceptibility, without affecting the lubricating performance of the base oil at relatively low temperatures, and minimises friction at the boundary lubrication regime during oil decomposition. Thus, it can be seen that a high-performing solid lubricant is crucial for a hybrid lubrication mode to achieve continuous lubrication over a wide range of temperatures.

Rhenium is a grayish colored metal, rare in nature, with many attractive properties that have proven useful in superalloys, the petrochemical industry, electrodes for fuel cells and advanced catalytic applications. ${ }^{17-23}$ The increased availability of rhenium and greater knowledge of its chemistry have excited increasing research on its lubricating applications. Researchers have shown that some rhenium oxides possess a friction-reducing quality at high temperature. The Co-Cu-Re alloy and $\mathrm{Ni}-\mathrm{Cu}-\mathrm{Re}$ alloy are endowed with high-temperature self-lubricating behavior due to the production of rhenium oxides, which can effectively reduce the friction coefficient between rubbing pairs. ${ }^{\mathbf{2 4 2 5}}$ Moreover, taking the cost of rhenium into consideration, the perrhenate form of the metal is particularly attractive due to its distinct double oxide composition and unique crystal structure, which suggest its potential for the development of lubrication materials for a wide range of temperatures. The perrhenates as double metal oxides have relatively low hardness and slip more easily compared with single metal oxides, especially at elevated temperature conditions. Several publications reveal that copper perrhenate, boron perrhenate, iron perrhenate and cobalt perrhenate exhibit relatively low friction coefficients at high temperature. $^{26-28}$ This has been attributed to the physical adsorption of a soft film composed of perrhenate formed on the rubbed surface, which provides the materials with excellent properties for minimizing friction. In addition, rare earth elements have received widespread attention for their distinct physical and chemical properties in engineering applications. The research achievements on the lubricating performance of materials containing rare earths are impressive. For example, rare earth compounds used as lubricants have significant antifriction effects, such as $\mathrm{LaF}_{3}$ and $\mathrm{La}(\mathrm{OH})_{3} \cdot{ }^{29-32}$ As a consequence, it can be expected that the promising candidate perrhenate, combined with lanthanum and a base oil, could fulfill a hybrid lubrication function at various temperatures.

In the light of research findings on the lubricating materials mentioned above, the purpose of the present work is to provide a comprehensive study of the tribological performances of lanthanum perrhenate incorporated with pentaerythritol ester (PETE) for wide temperature range applications. Lanthanum perrhenate was prepared via the aqueous solution method, and steadily dispersed into PETE base oil with the assistance of sorbitan tristearate (Span60) and polyoxyethylene sorbitan fatty acid ester (Tween60). The effect of the lanthanum perrhenate additive on the lubricating performances of the PETE base oil for contact between silicon nitride and superalloys at a temperature range of $22{ }^{\circ} \mathrm{C}$ to $600{ }^{\circ} \mathrm{C}$ was investigated. Meanwhile, the mechanisms of its significantly improved friction-reducing performance are also analyzed and discussed in relation to the lubricant's intrinsic characteristics, worn surface features and formation of a protective layer via rubbing action.

\section{Materials and methods}

\subsection{Materials}

Commercially attained rhenium powders (99.99\% purity) were provided by Zhonglai New Materials Co. Ltd. Hydrogen peroxide solution and lanthanum oxide $\left(\mathrm{La}_{2} \mathrm{O}_{3}\right)$ powders were also commercially obtained from Sinopharm Group Co., Ltd. Other chemical reagents used in the preparation were of A.R. grade. The synthetic process of lanthanum perrhenate was as follows. Samples of $0.5586 \mathrm{~g}$ (approximately $0.003 \mathrm{~mol}$ ) of rhenium powders were added into $20 \mathrm{ml}$ hydrogen peroxide solution (30\% concentration) with stirring until the solution transformed from colorless into light grey. After that, the excessive hydrogen peroxide solution was evaporated and a perrhenic acid solution $\left(\mathrm{HReO}_{4}\right)$ was obtained. Then, $0.212 \mathrm{~g}$ (approximately $0.00065 \mathrm{~mol}$ ) samples of lanthanum oxide powders were added into freshly prepared $\mathrm{HReO}_{4}$ solution, and the reaction was carried out to completion under stirring conditions at room temperature. The redundant residues were filtered out at the end of the reaction, and the reaction solution was kept over a water bath at $80^{\circ} \mathrm{C}$ for 1 hour to ensure the generation of dry powders. Finally, the synthetic powders were removed from the water bath and maintained at room temperature.

PETE, a synthetic lubricating oil for aviation applications, was selected as the base oil because of its outstanding physicalchemical properties, good oxidation resistance, and high thermal stability. The fundamental physical-chemical index parameters are listed in Table 1 . In order to obtain a stable dispersion mixture of base oil containing $\mathrm{La}\left(\mathrm{ReO}_{4}\right)_{3}$ additive, Span60 and Tween60 were chosen as surface active agents (SA) to emulsify the PETE. For example, the preparation of the mixture of $5 \mathrm{~g}$ oil containing $0.5 \mathrm{wt} \% \mathrm{La}\left(\mathrm{ReO}_{4}\right)_{3}$ was as follows. Firstly, $0.025 \mathrm{~g} \mathrm{La}\left(\mathrm{ReO}_{4}\right)_{3}$ powder was weighed out and converted to a supersaturated aqueous solution. Then, $0.045 \mathrm{~g}$ of Span60 and $0.005 \mathrm{~g}$ of Tween60 were weighed out (a mass ratio of $90 \%$ Span60:10\% Tween60) and combined into an SA composite. Then, $0.05 \mathrm{~g}$ of the SA composite was slowly added into the base oil with supersonic vibration over a period of 30 min duration to reduce the surface tension of the base oil and create a stable interface. Subsequently, the supersaturated aqueous solution was added into the base oil containing SA and continually stirred at a rotation speed of $1500 \mathrm{rpm}$ for $10 \mathrm{~min}$ at a temperature of $130{ }^{\circ} \mathrm{C}$ until no obvious bubbling occurred. Mixture samples containing different concentrations of $\mathrm{La}\left(\mathrm{ReO}_{4}\right)_{3}$ additive prepared with the same dispersion technique were used under tribological conditions to achieve a series of comparative tests.

Powder X-ray diffraction (XRD) analyses of the synthesized powders were performed by a D/max-2500PC X-ray diffractometer with $\mathrm{Cu} \mathrm{K} \alpha$ radiation $(\lambda=0.154 \mathrm{~nm})$. Diffraction data were recorded for $2 \theta$ angles between $10^{\circ}$ and $90^{\circ}$. The morphology and the size of the synthesized product were obtained using field emission scanning electron microscopy (SEM, FEI INSPECT-F50). In order to evaluate the dispersion stability of lanthanum perrhenate in the base oil, a UV-3900 ultraviolet spectrophotometer was used to analyze the transmittances of 
Table 1 Physical and chemical properties of PETE

\begin{tabular}{lllll}
\hline Properties & $\begin{array}{l}\text { Flash point temperature } \\
\left({ }^{\circ} \mathrm{C}\right)\end{array}$ & $\begin{array}{l}\text { Pour point temperature } \\
\left({ }^{\circ} \mathrm{C}\right)\end{array}$ & $\begin{array}{l}\text { Kinematic viscosity, } \\
\mathrm{cSt} @ 40{ }^{\circ} \mathrm{C}\end{array}$ & $\begin{array}{l}\text { Kinematic viscosity, } \\
\mathrm{cSt} @ 100{ }^{\circ} \mathrm{C}\end{array}$ \\
\hline PETE & 270 & -60 & 42.55 & 5.8
\end{tabular}

PETE containing $\mathrm{La}\left(\mathrm{ReO}_{4}\right)_{3}$ at different times $(0 \mathrm{~h}, 3 \mathrm{~h}, 6 \mathrm{~h}, 12 \mathrm{~h}$, $24 \mathrm{~h}, 36 \mathrm{~h}, 48 \mathrm{~h}, 60 \mathrm{~h}$ and $72 \mathrm{~h}$ ) and reverse osmosis (RO) water was selected as the reference solution. The differential thermal analysis/thermogravimetry (DTA/TG) analyses of PETE, PETE with SA, and PETE containing lanthanum perrhenate additive were carried out by a SETSYS Evolution 18 thermal analyzer. The temperature-control program was set to increase from $150{ }^{\circ} \mathrm{C}$ to $700{ }^{\circ} \mathrm{C}$ with a heating rate of $10{ }^{\circ} \mathrm{C} \mathrm{min}^{-1}$ in an ambient atmospheric environment. The experimental sample mass was $12.74 \mathrm{mg}$, and the air velocity was $30 \mathrm{ml} \mathrm{min}^{-1}$. Additionally, pressure differential scanning calorimetry (PDSC) was used to investigate the effect of the lanthanum perrhenate additive on the thermal-oxidation stability of PETE using a TA Q2000 thermal analysis instrument. Portions of $1.5 \mathrm{mg}$ of each different sample were placed in the holders, and the heating rate was $10{ }^{\circ} \mathrm{C} \mathrm{min}^{-1}$ from room temperature to $350^{\circ} \mathrm{C}$ under an oxygen partial pressure of 3.5 MPa.

\subsection{Four-ball test}

The tribological characteristics in terms of the friction coefficients, maximum nonseizure load $\left(P_{\mathrm{B}}\right.$ value) and wear scar diameter (WSD) for different samples were examined using an MMU-10G four-ball tester manufactured by Jinan Shunmao Instrument Test Co., Ltd, Jinan, China. In a typical case, a steel ball (diameter $=12.7 \mathrm{~mm}$, hardness $=64-66 \mathrm{HRC}$ ) under a certain load was rotated against three static balls fixed in the lower holder. The $P_{\mathrm{B}}$ value tests were carried out following the Chinese National Standard GB3142/82 (equivalent to ASTM D 2783 ) testing method at a rotating rate of $1450 \mathrm{rpm}$ for $10 \mathrm{~s}$. The WSD tests were performed under an applied load of $392 \mathrm{~N}$ at a rotating speed of $1450 \mathrm{rpm}$ at ambient temperature, and the tests lasted for a duration of $30 \mathrm{~min}$. Before each test, the lower and upper ball holders and test balls were washed in an ultrasonic cleaner with acetone. The diameters of the wear scars on the lower steel balls were measured using an optical microscope and the process was repeated to obtain an average value in micrometers. The morphological features on the wear scars of lower steel balls lubricated by different samples were observed using an FEI INSPECT-F50 scanning electron microscope.

\subsection{Friction tests in a wide temperature range}

The tribological performances of different lubricating samples added to the contact interface of ceramic balls and a superalloy (GH4169) were evaluated on a ball-on-disc tribotester (UMT-2M, USA) under ambient conditions. A schematic diagram of the UMT-2M ball-on-disc frictional tester is shown in Fig. 1. The superalloy (composition: $\leq 0.08 \% \mathrm{C}, \leq 1.0 \% \mathrm{Co}, 2.8-3.3 \% \mathrm{Mo}$, $0.3-0.7 \% \mathrm{Al}, 0.75-1.15 \% \mathrm{Ti}, 17-21 \% \mathrm{Cr}, 50-55 \% \mathrm{Ni}$ and balance

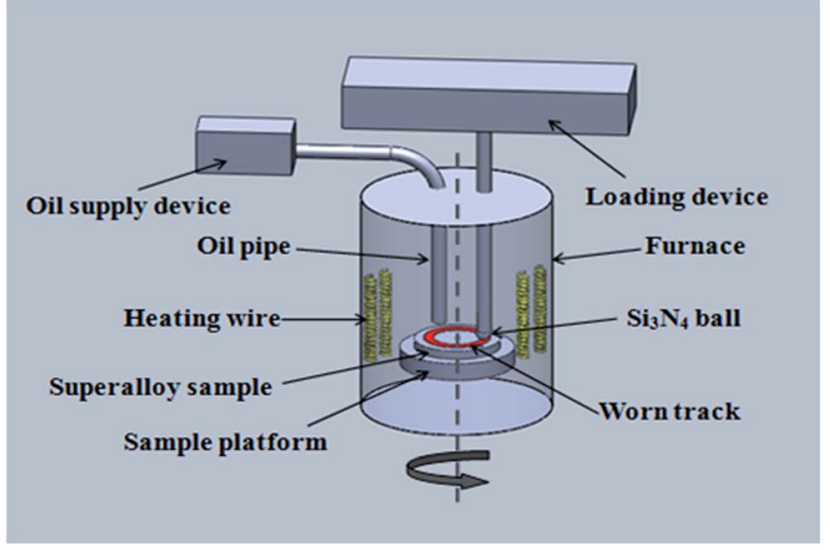

Fig. 1 Schematic illustration of UMT-2M ball-on-disc tribotester.

Fe, given as weight fractions) was formed into discs of size 50 $\mathrm{mm} \times 4 \mathrm{~mm}$, where $50 \mathrm{~mm}$ was the diameter. The superalloy surface was ground in an automatic polish-grinding machine at a speed of $600 \mathrm{rpm}$ with $100^{\#}, 400^{\#}, 800^{\#}, 1200^{\#}, 1500^{\#}, 2000^{\#}$ and $3000^{\#}$ abrasive papers. Then, the surface was fine polished using a polishing cloth with diamond paste under the same rotation speed to obtain a roughness of no more than $20 \mathrm{~nm}$. The counterpart was a commercial $\mathrm{Si}_{3} \mathrm{~N}_{4}$ ceramic ball with a diameter of $3 \mathrm{~mm}$. The selected experimental temperatures were $22{ }^{\circ} \mathrm{C}, 200{ }^{\circ} \mathrm{C}, 350{ }^{\circ} \mathrm{C}, 450{ }^{\circ} \mathrm{C}$ and $600{ }^{\circ} \mathrm{C}$. The tests were carried out at an applied load of $2 \mathrm{~N}$, sliding velocity of $40 \mathrm{~mm} \mathrm{~s}^{-1}$, and testing time of $8 \mathrm{~min}$. During the tests, the oil mixture with and without the $\mathrm{La}\left(\mathrm{ReO}_{4}\right)_{3}$ additive was added to the contact interface of the rubbing pair. Each experiment was repeated three times to ensure repeatability and reproducibility. The friction coefficient at each temperature was chosen as the average value of three measurements taken at regular intervals during the test.

The worn surface morphologies at different friction conditions were examined using an FEI INSPECT-F50 scanning electron microscope. The width values of the worn groove were investigated using a VHE-1000 digital microscope (KEYENCE, Japan). The chemical states of the worn surfaces were detected using X-ray photoelectron spectroscopy (XPS, ESCALAB250, USA). The XPS analysis was conducted at $150 \mathrm{~W}$ and a pass energy of $50.0 \mathrm{eV}$, using $\mathrm{Al}-\mathrm{K} \alpha$ radiation as the excitation source.

\section{Results and discussion}

\subsection{Synthesized materials characterization}

Fig. 2 shows the X-ray diffraction pattern of the synthesized product. Most of the observed diffraction peaks in the XRD 


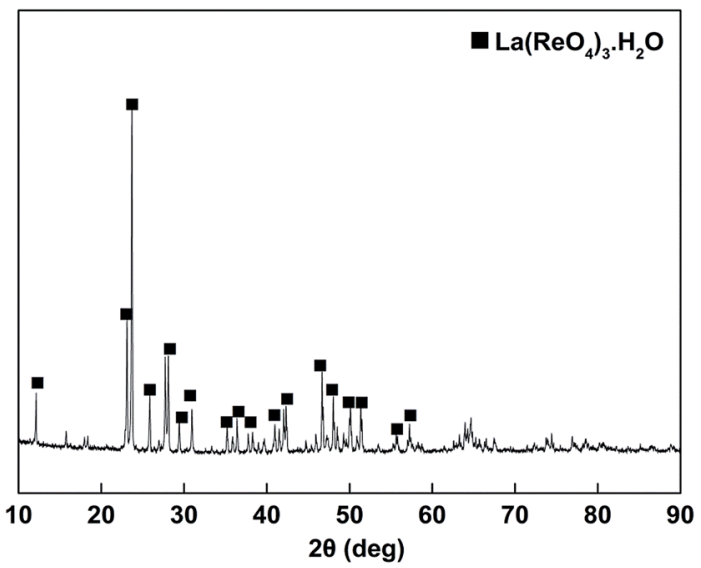

Fig. 2 XRD pattern of synthesized powder.

pattern were characteristic of the $\mathrm{La}\left(\mathrm{ReO}_{4}\right)_{3} \cdot \mathrm{H}_{2} \mathrm{O}$ phase, which was in accordance with the PDF 21-0455 data. However, there was no information about the crystal structure and crystal plane in the PDF data. Consequently, it was difficult to confirm the exact crystal plane indices of the major peaks located at $2 \theta=23.7^{\circ}, 23.1^{\circ}$ and $27.8^{\circ}$. Nevertheless, these characteristic peaks indicated that lanthanum perrhenate could be synthesized via simple processing of an aqueous solution of excessive lanthanum salt in a certain concentration of perrhenic acid. Additionally, the existence of crystal water showed that the synthesized product contained hydroxyl bonds, which implied that the lanthanum perrhenate would dissolve easily in water.

The morphological features of the synthesized lanthanum perrhenate were observed by SEM. Fig. 3 shows that the prepared powder was irregularly elliptical in shape, having a high aspect ratio with a grain size of about $10-30 \mu \mathrm{m}$. The crystallization process led to the growth of grains with different grain sizes of the product. It could be seen that most of the powders contained microscopic cracks and gaps, which enhanced their shear susceptibility.

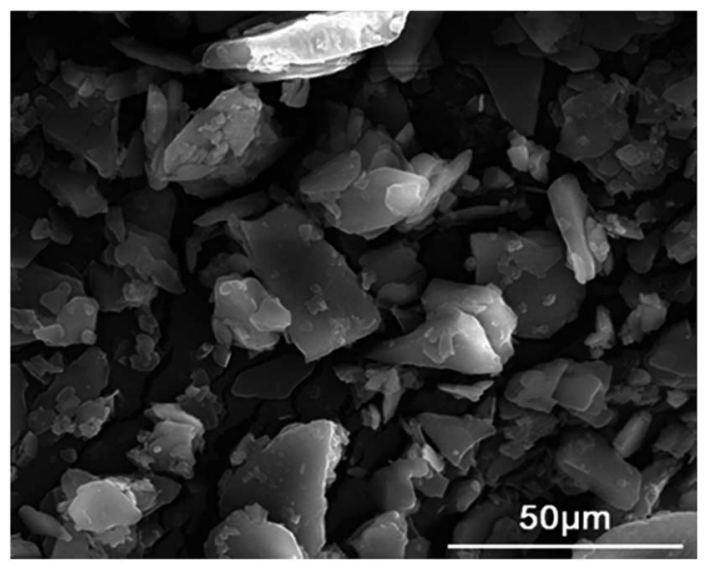

Fig. 3 SEM micrograph of synthesized powder.

\subsection{Dispersion characterization}

The dispersion stability of the different samples was examined by ultraviolet spectrophotometry. The transmittances, which are routinely employed to evaluate the extent of dispersion stability, are shown in Fig. 4. It was clearly evident that the transmittances of the samples dropped with the increase of additive concentration under the same test duration on account of the suspended substances. Meanwhile, the transmittances of the samples slightly rose with increasing time because of the deposition of suspended particles, and approximately stabilized after 24 hours. The low deposition rate and long-term stability of the suspension indicated that the chosen dispersion technique could attain oil mixtures with high dispersion stability by changing the surface structure of the base oil.

\subsection{Thermal stability}

In order to determine the thermal behavior of the oil mixture, DTA/TG and PDSC were used to analyze the tolerance of the samples to thermal-oxidative degradation. Fig. 5 shows that obvious weight loss of all the samples occurred at temperatures between $200{ }^{\circ} \mathrm{C}$ and $340{ }^{\circ} \mathrm{C}$. The exothermic peak of PETE was located at $321{ }^{\circ} \mathrm{C}$, suggesting that the PETE as a base oil possessed excellent thermal stability. After modification with the SA, the exothermic peak of the sample appeared at $308{ }^{\circ} \mathrm{C}$. This indicated that the addition of the SA did not strongly impact on the thermal stability of the base oil. The exothermic peak of PETE containing $0.5 \mathrm{wt} \% \mathrm{La}\left(\mathrm{ReO}_{4}\right)_{3}$ additive was at $323{ }^{\circ} \mathrm{C}$, which demonstrated that the presence of $\mathrm{La}\left(\mathrm{ReO}_{4}\right)_{3}$ hardly affected the PETE transition temperature. Moreover, the incipient oxidation temperatures of the different samples determined by PDSC are shown in Table 2. The values of incipient oxidation temperature of PETE, PETE with SA and PETE containing $0.5 \mathrm{wt} \% \mathrm{La}\left(\mathrm{ReO}_{4}\right)_{3}$ additive were $218.44{ }^{\circ} \mathrm{C}$, $218.06^{\circ} \mathrm{C}$ and $216.07^{\circ} \mathrm{C}$, respectively. Therefore, the addition of an inorganic additive and organic surfactants did not appear to affect the oxidative stability of the base oil.

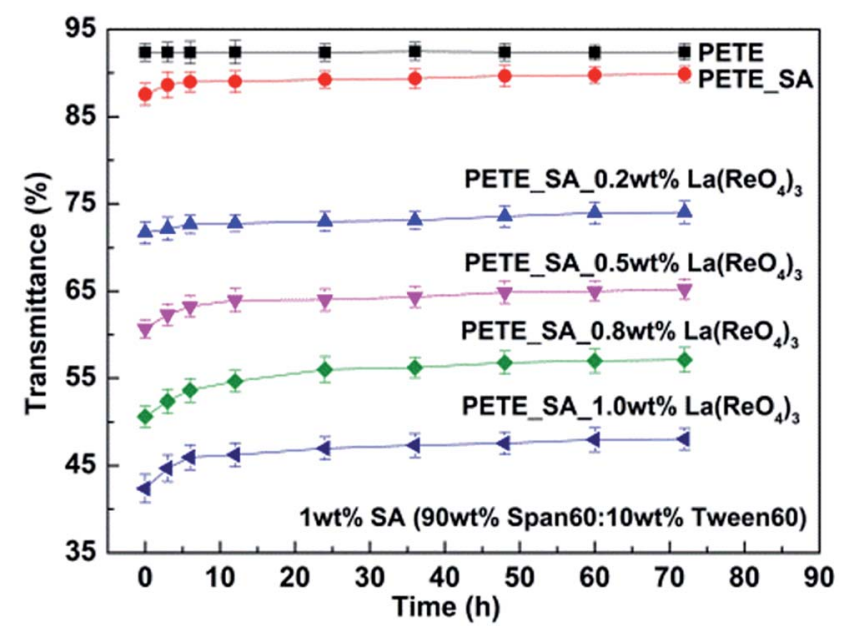

Fig. 4 Transmittances of PETE containing different concentrations of $\mathrm{La}\left(\mathrm{ReO}_{4}\right)_{3}$ additive with the inclusion of SA. 

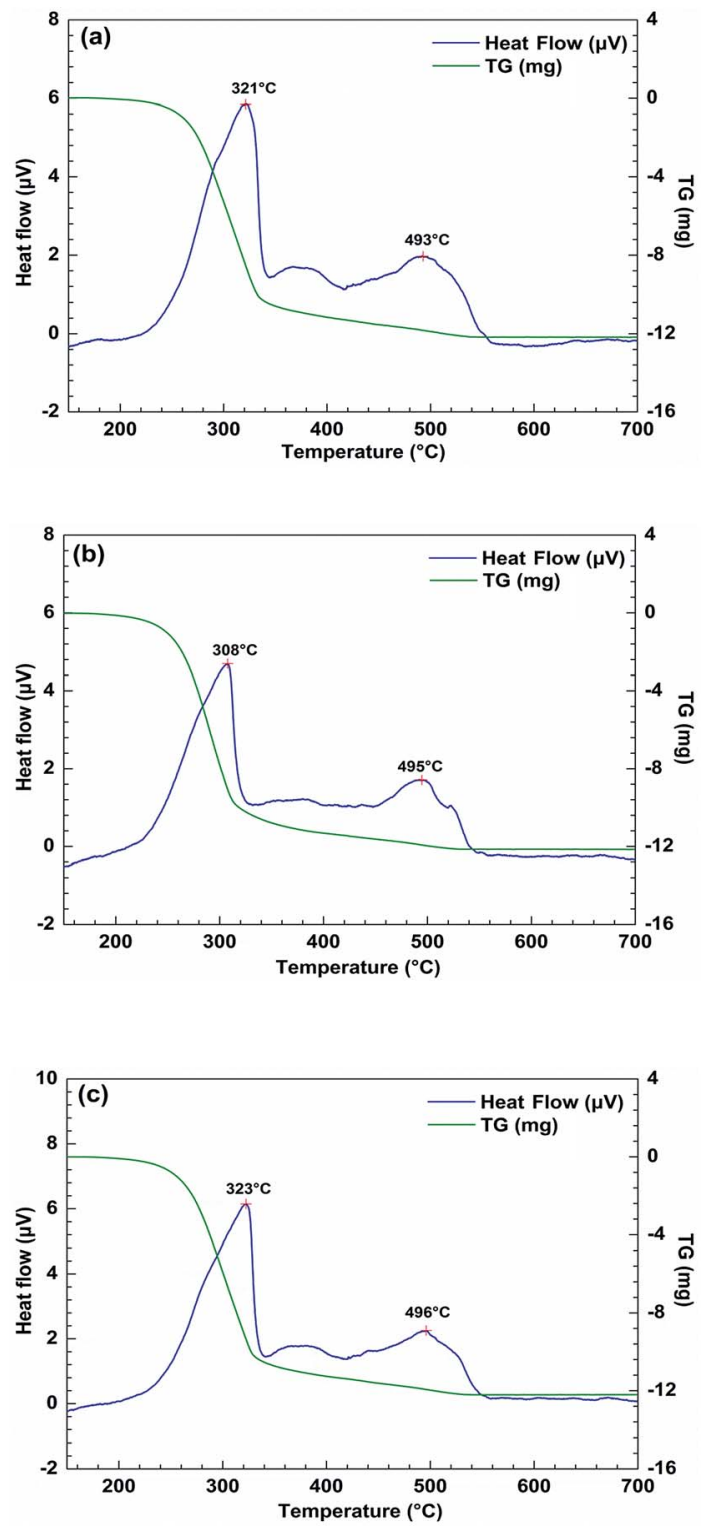

Fig. 5 DTA/TG curves of different lubricating samples: (a) PETE; (b) PETE_SA; (c) PETE_SA_0.5 wt\% $\mathrm{La}\left(\mathrm{ReO}_{4}\right)_{3}$.

Table 2 Values of incipient oxidation temperature of different lubricating samples

\begin{tabular}{lcll}
\hline Lubricants & PETE & PETE_SA & $\left.\begin{array}{l}\text { PETE_SA_0.5 } \\
\text { wt\% La(ReO }\end{array}\right)_{3}$ \\
\hline $\begin{array}{l}\text { Incipient oxidation } \\
\text { temperature }\left({ }^{\circ} \mathrm{C}\right)\end{array}$ & 218.44 & 218.06 & 216.07
\end{tabular}

\subsection{Four-ball test}

The synthesized $\mathrm{La}\left(\mathrm{ReO}_{4}\right)_{3}$ powders were evaluated to explore their lubricating potential using an MMU-10G four-ball test instrument at room temperature conditions. Fig. 6 shows the average friction coefficients, the wear scar diameters, and the maximum nonseizure loads for PETE containing different doses

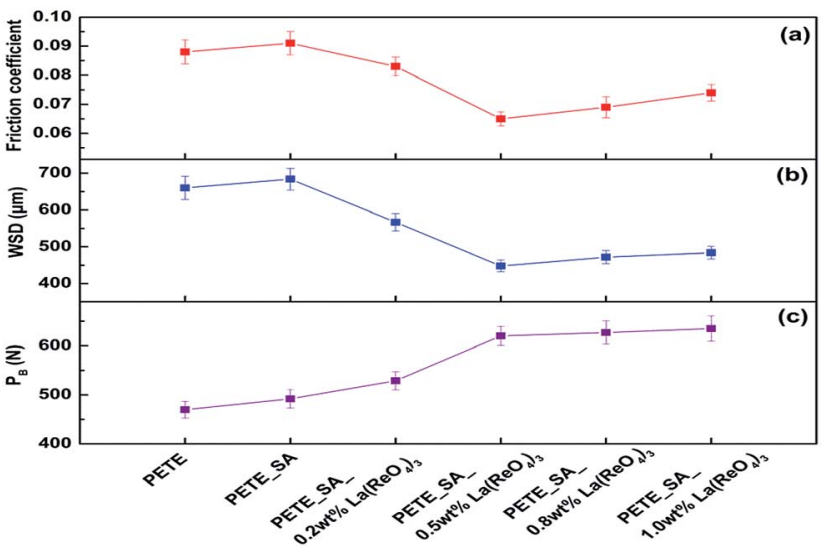

Fig. 6 Effect of different concentrations of $\mathrm{La}\left(\mathrm{ReO}_{4}\right)_{3}$ additive on the average values of friction coefficient, wear scar diameter and maximum nonseizure load: (a) friction coefficient; (b) wear scar diameter; (c) maximum nonseizure load.

of $\mathrm{La}\left(\mathrm{ReO}_{4}\right)_{3}$ together with a dose of the SA, under an applied load of $392 \mathrm{~N}$. The average friction coefficient, WSD and $P_{\mathrm{B}}$ value of the base oil were $0.088,661 \mu \mathrm{m}$ and $470 \mathrm{~N}$, respectively. After the addition of SA, those values of average friction coefficient, WSD and maximum nonseizure load remained similar, suggesting that the addition of SA did not impair the tribological properties of the base oil. The values of friction coefficient and WSD showed similar trends to one another with the increasing concentration of $\mathrm{La}\left(\mathrm{ReO}_{4}\right)_{3}$ in the PETE, in that they initially decreased significantly and then increased with increasing concentration. The lowest friction coefficient and smallest WSD were found at the $\mathrm{La}\left(\mathrm{ReO}_{4}\right)_{3}$ concentration of $0.5 \mathrm{wt} \%$. This illustrated that $\mathrm{La}\left(\mathrm{ReO}_{4}\right)_{3}$ substantially improved the frictionreducing performance. The increase of the friction coefficient and WSD with excess amounts of $\mathrm{La}\left(\mathrm{ReO}_{4}\right)_{3}$ led to the aggregation of $\mathrm{La}\left(\mathrm{ReO}_{4}\right)_{3}$ at certain high-friction regions, which inhibited its continuous supply to the contact interfaces. The $P_{\mathrm{B}}$ values of PETE containing $\mathrm{La}\left(\mathrm{ReO}_{4}\right)_{3}$ particles were enhanced with increasing doses of the synthesized $\mathrm{La}\left(\mathrm{ReO}_{4}\right)_{3}$ additive, and the maximum value was obtained when the additive concentration was $1.0 \mathrm{wt} \%$. We speculate that the $\mathrm{La}\left(\mathrm{ReO}_{4}\right)_{3}$ powders strongly promoted the antiwear property of the base oil by reacting with the wear surface to form a protective layer containing $\mathrm{La}\left(\mathrm{ReO}_{4}\right)_{3}$ during the test.

To investigate the lubrication mechanism of $\mathrm{La}\left(\mathrm{ReO}_{4}\right)_{3}$ as an additive, SEM was used to analyze the wear scars after the fourball test. Fig. 7 shows typical SEM images of the wear scars lubricated by base oil, base oil containing SA only, base oil with $0.5 \mathrm{wt} \% \mathrm{La}\left(\mathrm{ReO}_{4}\right)_{3}$ additive and with $1.0 \mathrm{wt} \% \mathrm{La}\left(\mathrm{ReO}_{4}\right)_{3}$ additive. It can be seen from Fig. 7a that the wear scar lubricated with pure lubricating oil was rough and displayed signs of severe furrows. This demonstrated that although the lubricating oil had acceptable tribological properties, serious wear occurred after extended testing times. The wear scar lubricated by base oil with SA alone also displayed obvious furrows and scuffing (Fig. 7b). In contrast, the wear scars lubricated by oil with $0.5 \mathrm{wt} \% \mathrm{La}\left(\mathrm{ReO}_{4}\right)_{3}$ additive or $1.0 \mathrm{wt} \% \mathrm{La}\left(\mathrm{ReO}_{4}\right)_{3}$ additive displayed very little scuffing along the sliding direction, and the 

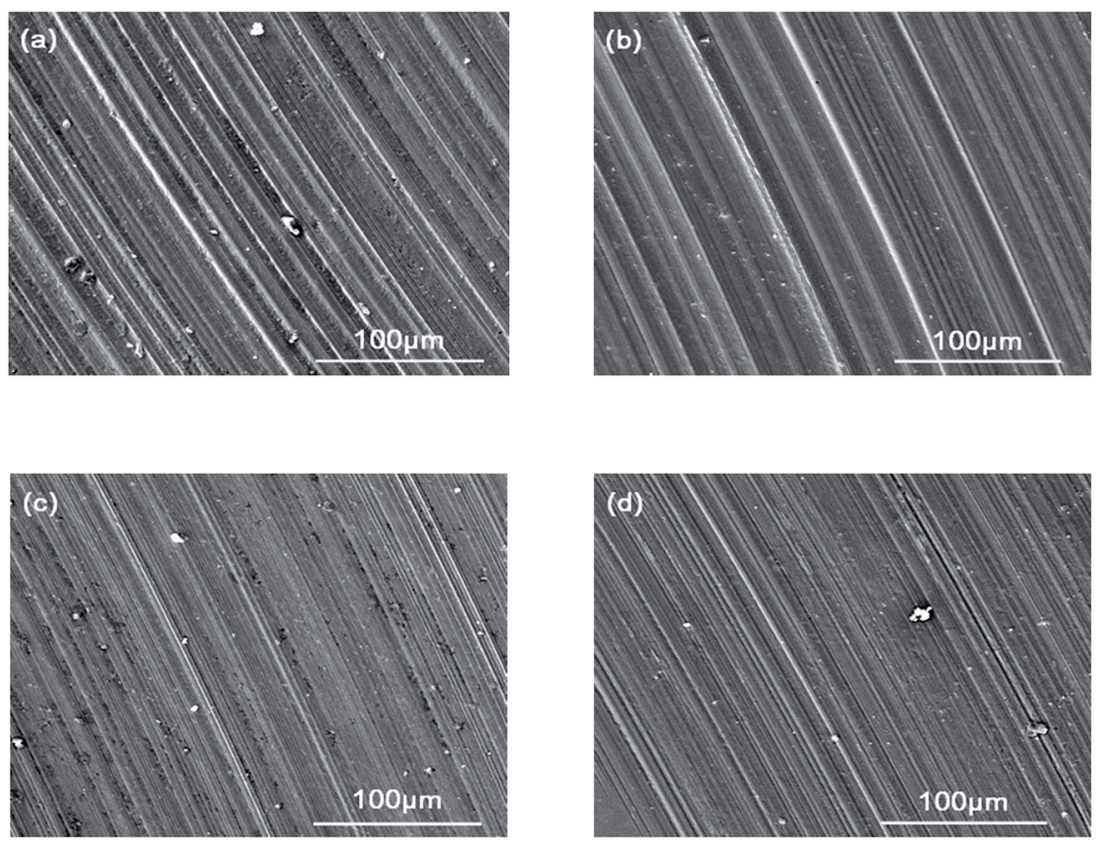

Fig. 7 SEM images of wear scars lubricated by different lubricating samples: (a) PETE; (b) PETE_SA; (c) PETE_SA_0.5 wt\% La(ReO 4$)_{3}$; (d) PETE_SA_1.0 wt\% $\mathrm{La}\left(\mathrm{ReO}_{4}\right)_{3}$.

wear scars were relatively narrow and shallow (Fig. 7c and d). This implied that the synthesized $\mathrm{La}\left(\mathrm{ReO}_{4}\right)_{3}$ as a lubricating additive in PETE was effective in reducing the wear of the steelsteel pair, which may be attributed to the formation of a positive protection film on the contact surface. The morphological features were in agreement with the corresponding friction and wear behaviour.

\subsection{Friction coefficients for a wide temperature range}

Fig. 8 exhibits the friction coefficients of different samples added to the rubbing contact surface at various temperatures during a ball-on-disc friction test with circular motion. At room temperature and $200{ }^{\circ} \mathrm{C}$, the friction coefficients of the base oil

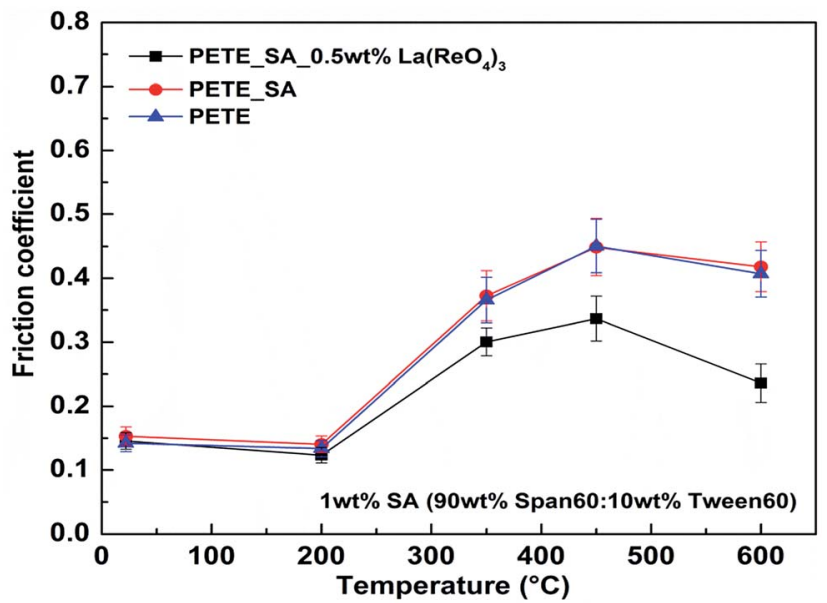

Fig. 8 Average friction coefficient values of different lubricating samples at various temperatures. were about 0.142 and 0.133 , suggesting that the oil-film played a role in lubricating the surface contact at relatively low temperature. Meanwhile, the oil containing SA only had similar values of friction coefficient to the pure oil, which indicated that the addition of SA did not undermine the oil-film lubrication. The friction coefficient of base oil containing $0.5 \mathrm{wt} \% \mathrm{La}\left(\mathrm{ReO}_{4}\right)_{3}$ additive was slightly lower than that of pure base oil, in accordance with the four-ball test result. This further illustrated that the $\mathrm{La}\left(\mathrm{ReO}_{4}\right)_{3}$ additive was beneficial to the base oil during the process of oil-film lubrication. When the temperature reached more than $350{ }^{\circ} \mathrm{C}$, the oil began to undergo oxidative decomposition, which resulted in a rapid increase of the friction coefficients of the base oil and the oil with SA only. In contrast, the friction coefficient of the oil with $\mathrm{La}\left(\mathrm{ReO}_{4}\right)_{3}$ additive rose only within a small range, and remained much lower than that of the base oil, indicating that the $\mathrm{La}\left(\mathrm{ReO}_{4}\right)_{3}$ additive provided a lubrication function at elevated temperature. The friction coefficient observed in this research was about 0.23 for PETE containing $\mathrm{La}\left(\mathrm{ReO}_{4}\right)_{3}$ additive at $600{ }^{\circ} \mathrm{C}$. As was expected, introducing the lanthanum perrhenate additive contributed to the reduction of the friction coefficients in the high temperature regime. This can be explained as follows. During the friction test between the rubbing pair at high temperature, the contact zone had high frictional heat, and thus offered a surface with high energy for chemical activity. This promoted the formation of a cohesive protective layer containing an $\mathrm{La}\left(\mathrm{ReO}_{4}\right)_{3}$ composite at the interface. Meanwhile, the thermal softening effect allowed the $\mathrm{La}\left(\mathrm{ReO}_{4}\right)_{3}$ composite to be easily sheared under friction force, which effectively minimized the friction coefficient. 


\subsection{Worn surface morphology and worn track width analysis}

To further illustrate the role of the $\mathrm{La}\left(\mathrm{ReO}_{4}\right)_{3}$ additive and the wear mechanisms, the worn surface morphologies at increasing temperatures are presented in Fig. 9. As can be seen from Fig. 9a-c, serious plastic deformations were observed, accompanied with parallel ploughing along the sliding direction, on all the worn surfaces lubricated with base oil at elevated temperatures. Flakes had already detached and delamination pits were found on the worn region. This can be explained as the result of direct contact between the rubbing pair owing to oil- film lubrication failure with oil flash explorations at high temperature, leading to surface damage of the metal material.

It can be seen from Fig. 9d-i that the addition of $0.5 \mathrm{wt} \%$ $\mathrm{La}\left(\mathrm{ReO}_{4}\right)_{3}$ additive clearly altered the worn morphologies. At $350{ }^{\circ} \mathrm{C}$, a relatively shallow plough and some very small quantities of powder were observed on the worn surface. To determine the composition of the material on the surface, EDS analysis was performed. The result showed that the main elements were $\mathrm{La}, \mathrm{Re}, \mathrm{O}, \mathrm{Ni}, \mathrm{Fe}$, and $\mathrm{Cr}$, with smaller quantities of other elements, which attached to the $\mathrm{La}\left(\mathrm{ReO}_{4}\right)_{3}$ additive and the superalloy. This indicated that the addition of the $\mathrm{La}\left(\mathrm{ReO}_{4}\right)_{3}$
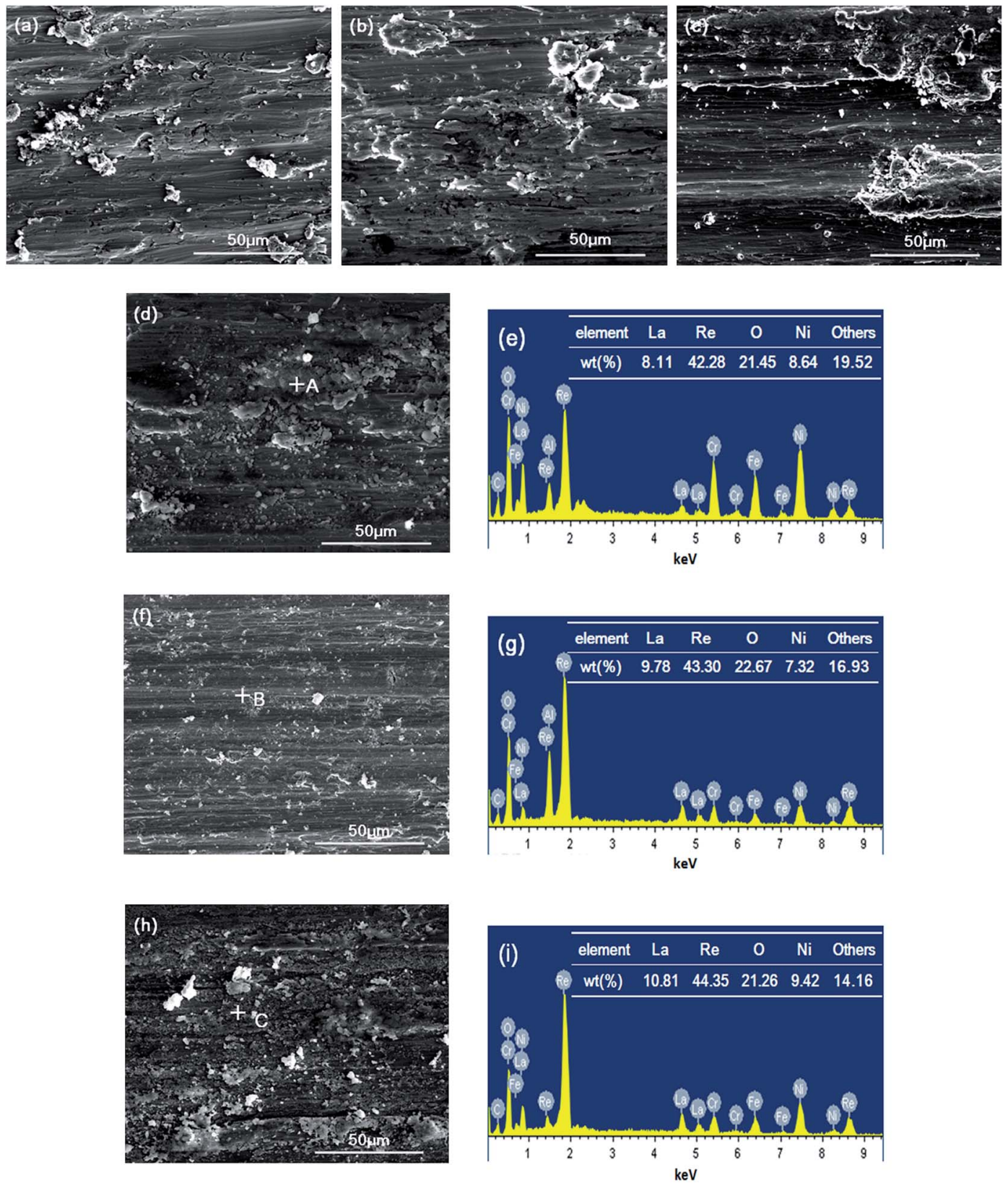

Fig. 9 SEM images of the worn surfaces of the superalloy disc after sliding friction test lubricated by different lubricating samples at various temperatures, and EDS results of marked points: (a) $350{ }^{\circ} \mathrm{C}, \mathrm{PETE}$; (b) $450{ }^{\circ} \mathrm{C}$, PETE; (c) $600{ }^{\circ} \mathrm{C}, \mathrm{PETE}$; (d) $350{ }^{\circ} \mathrm{C}, \mathrm{PETE} \_\mathrm{SA} \_0.5$ wt $\%$ La(ReO 4$)_{3}$; (e) EDS result for point A; (f) $450{ }^{\circ} \mathrm{C}$, PETE_SA_0.5 wt\% $\mathrm{La}\left(\mathrm{ReO}_{4}\right)_{3}$; (g) EDS result for point B; (h) $600{ }^{\circ} \mathrm{C}, \mathrm{PETE} \_\mathrm{SA} \_0.5 \mathrm{wt} \% \mathrm{La}(\mathrm{ReO})_{3}$; (i) EDS result for point $C$. 
additive minimized the direct contact between the rubbing pair, thus reducing friction. At $450{ }^{\circ} \mathrm{C}$, the worn track showed milder plastic deformations and a softer additive, blended with debris, compared with that lubricated by the base oil. Clearly, the $\mathrm{La}\left(\mathrm{ReO}_{4}\right)_{3}$ additive was closely deposited on the worn surface to weaken the attraction between the friction pair at high temperature. When the temperature reached $600{ }^{\circ} \mathrm{C}$, the plastic deformations were significantly shallower, and a continuous dense layer appeared on the worn surface. Although some surface peeling occurred, the protective layer and Ni-based superalloy were observed to be closely combined. The EDS results therefore proved that the chemical components of the $\mathrm{La}\left(\mathrm{ReO}_{4}\right)_{3}$ additive were maintained in the layer, which acted as a wear-resistant holder to bear most of the contact stress.

The changes in the average worn track width were measured to quantify the lubrication performance of $\mathrm{La}\left(\mathrm{ReO}_{4}\right)_{3}$ in the base oil (Fig. 10). It was observed that the peak values of the wear track width appeared at $450{ }^{\circ} \mathrm{C}$, which was consistent with the temperature dependence of the friction coefficients. Compared with the base oil, the wear track width decreased by $3.0 \%, 6.5 \%$ and $11.6 \%$ when lubricated by oil with $0.5 \mathrm{wt} \% \mathrm{La}\left(\mathrm{ReO}_{4}\right)_{3}$ additive at $350{ }^{\circ} \mathrm{C}, 450{ }^{\circ} \mathrm{C}$ and $600{ }^{\circ} \mathrm{C}$, respectively. Usually, an increase in plastic deformation results in a wider track width. The $\mathrm{La}\left(\mathrm{ReO}_{4}\right)_{3}$ additive in the base oil gave relatively minimal plastic deformation and performed an outstanding antifriction function at $600{ }^{\circ}$ C. Moreover, Fig. 11 displays the XRD patterns of $\mathrm{La}\left(\mathrm{ReO}_{4}\right)_{3}$ powders after heat treatment for 10 minutes at different temperatures. Relative to the crystalline structure at room temperature, the $\mathrm{La}\left(\mathrm{ReO}_{4}\right)_{3}$ composite did not experience phase transformation or decomposition, which illustrated that $\mathrm{La}\left(\mathrm{ReO}_{4}\right)_{3}$ possessed thermal stability within the tested temperature scope.

The results above implied that the $\mathrm{La}\left(\mathrm{ReO}_{4}\right)_{3}$ composite could adhere to the contact surface by means of physical interaction at elevated temperature during the sliding process. The added $\mathrm{La}\left(\mathrm{ReO}_{4}\right)_{3}$ composite was continuously ground into fine particles under applied load as the temperature increased, and combined with native oxides from the superalloy disc to form a protective layer on the interface between the $\mathrm{Si}_{3} \mathrm{~N}_{4}$ ball and the superalloy, which effectively reduced the adhesive

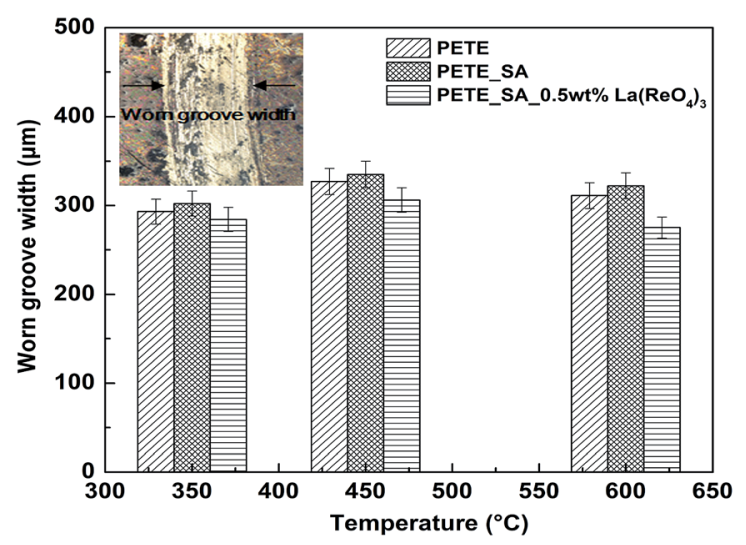

Fig. 10 Average width values of the worn track lubricated by different lubricating media.

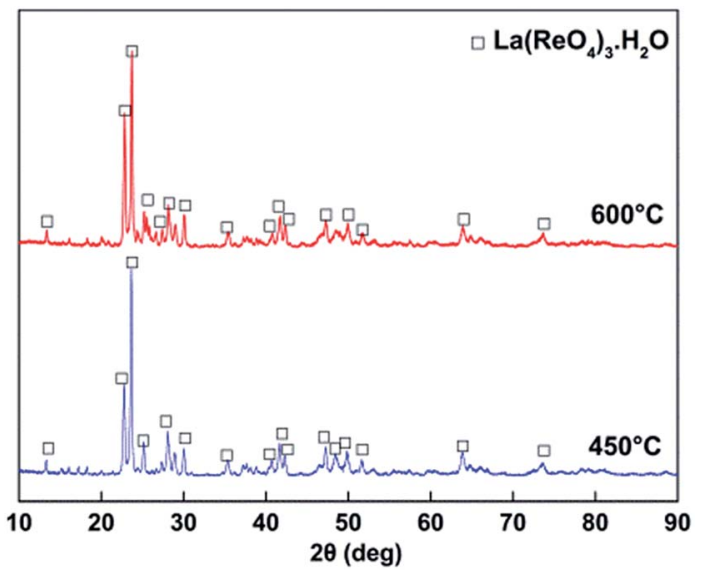

Fig. 11 XRD patterns of $\mathrm{La}\left(\mathrm{ReO}_{4}\right)_{3}$ powder after heat treatment at different temperatures for 10 minutes.

wearing and resulted in a low friction coefficient. In addition, the high temperature properties and intrinsic softness of the composite were beneficial to the formation of a continuous layer, which could firmly combine with the metal matrix.

\subsection{XPS analysis}

In order to determine the distribution of lubricating phases in the protective layer, XPS was used to characterize the surface components and chemical states of the worn surface lubricated with PETE containing $\mathrm{La}\left(\mathrm{ReO}_{4}\right)_{3}$ additive at $600{ }^{\circ} \mathrm{C}$. The XPS survey (Fig. 12a) revealed the presence of several elements from the worn surface including carbon (C), oxygen (O), lanthanum (La), rhenium (Re), nickel (Ni), iron (Fe) and chromium (Cr). Fig. 12b-h presents the narrow scan analysis of the surface elements. In the carbon spectrum, the C1s peaks located at $283.72 \mathrm{eV}$ and $284.75 \mathrm{eV}$ were the main components and were attributed to $\mathrm{C}-\mathrm{C}$ and $\mathrm{C}-\mathrm{O}$ bonds of organic compounds, which suggested that the decomposition products of the base oil were adsorbed on the worn surface. ${ }^{33}$ Another peak at $286.35 \mathrm{eV}$ was assigned to the $\mathrm{COO}$ functional group from the additional surfactants. Moreover, environmental contamination during the sliding test or the addition of an impurity during the wireelectrode cutting process may have contributed to this peak. As for oxygen, the peaks in the 01s spectrum were located at $529.11 \mathrm{eV}$ and $530.22 \mathrm{eV}$, which represented the $\mathrm{ReO}_{4}{ }^{-}$ion and some native oxides from the superalloy during the sliding test. The peak located at $531.09 \mathrm{eV}$ was associated with oxygencontaining functional groups. ${ }^{34,35}$ The La3d spectrum exhibited an intense peak around $836.9 \mathrm{eV}$ corresponding to the $\mathrm{La}^{3+}$ ion. The main Re4f peak at $45.53 \mathrm{eV}$ corresponded to absorption by Re originating from lanthanum perrhenate. Taken together, the XPS results indicated that the $\mathrm{La}\left(\mathrm{ReO}_{4}\right)_{3}$ composite existed on the worn surface and did not undergo phase transformation, which was in keeping with the XRD results. In addition, it can be seen from Fig. 12e-h that the component elements of nickel, iron and chromium were present in oxidized forms. This resulted from the plastic deformation, crack initiation and surface aviation that occurred during the friction test, which 

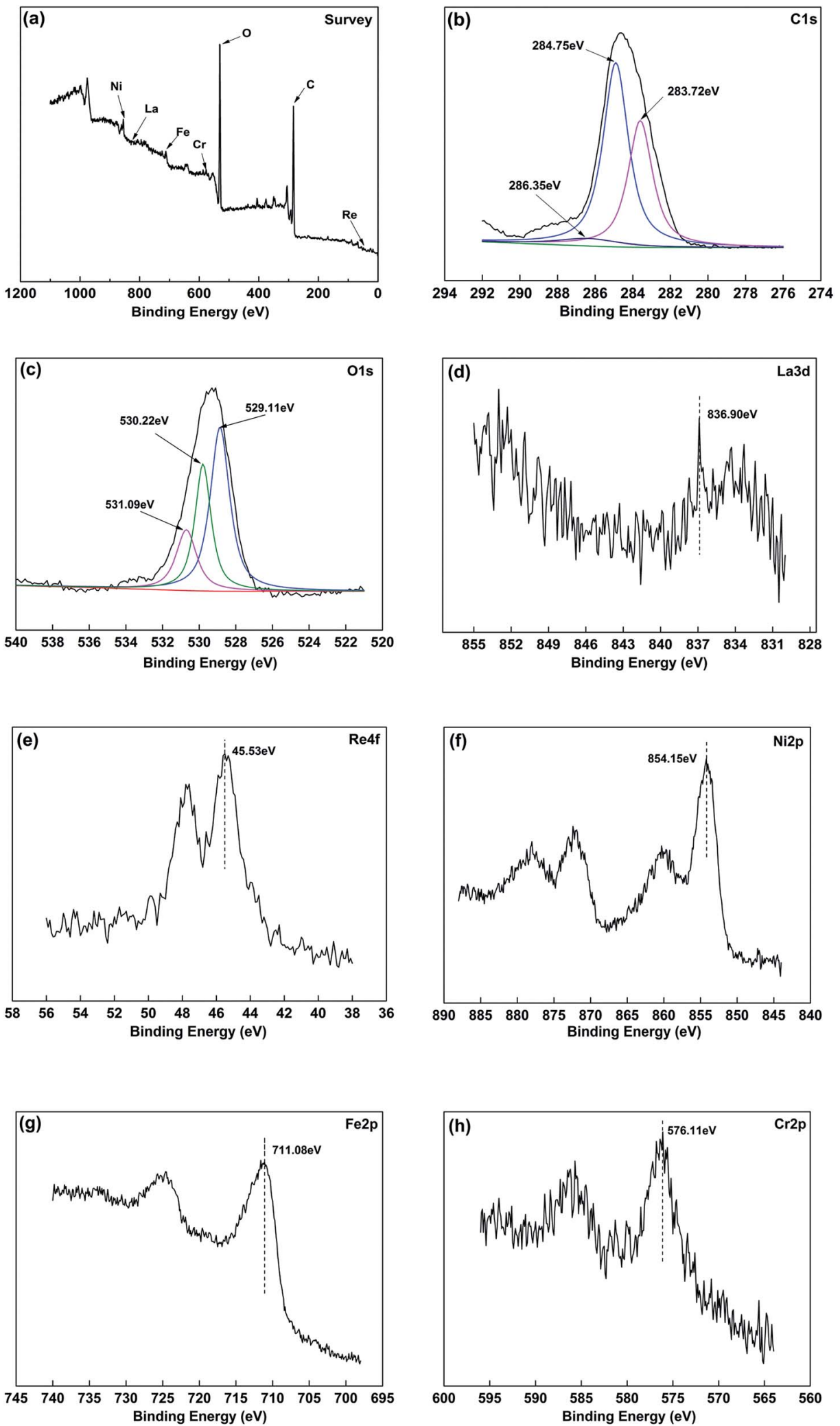

Fig. 12 XPS spectra of major elements on the worn surface of the superalloy disc lubricated by PETE containing $0.5 \mathrm{wt} \% \mathrm{La}\left(\mathrm{ReO} \mathrm{O}_{3}\right.$ after sliding test at $600{ }^{\circ} \mathrm{C}$ : (a) survey; (b) C1s; (c) O1s; (d) La3d; (e) Re4f; (f) Ni2p; (g) Fe2p; (h) Cr2p.

promoted the diffusion of ambient oxygen and its reaction with the superalloy matrix, which was prone to oxidation. Moreover, the XPS analysis of the sample lubricated by pure PETE also displayed the peaks associated with the oxidized states of $\mathrm{Ni}, \mathrm{Fe}$ and $\mathrm{Cr}$. The results above indicated that the $\mathrm{La}\left(\mathrm{ReO}_{4}\right)_{3}$ composite contributed the main lubricating power of the 
protective layer, although the native oxides of the superalloy on the worn track also played a minor role in lubrication. Thus, the improvement of tribological performance could be attributed to the formation of the $\mathrm{La}\left(\mathrm{ReO}_{4}\right)_{3}$ composite blended with the layer of native oxides on the worn surface. The layer acted as a protective covering and effectively reduced the direct contact of ball and disc.

\subsection{Cross-section analysis}

In a complex process involving oxygen diffusion, contact asperity and grinding at high temperature, the constant alternation of oxidation-friction removal-reoxidation took place on the Ni-based superalloy surface. The native oxide layer from the superalloy was firm and brittle, making it liable to shed from the interface under applied load and friction force. Thus, it was unable to form a stable protective layer with the function of protection against oxidation and prevention of direct contact of the rubbing pair. The cross-section SEM image of the worn surface lubricated by PETE oil with $0.5 \mathrm{wt} \% \mathrm{La}\left(\mathrm{ReO}_{4}\right)_{3}$ after friction testing at $600{ }^{\circ} \mathrm{C}$, together with the EDS spectrum of the marked point, are given in Fig. 13. The protective layer had a maximum thickness of 4-5 $\mu \mathrm{m}$ and presented loose features. The layer was firmly combined with the superalloy matrix debris, and no obvious separation between the protective layer and the superalloy could be seen in the cross-section. The EDS investigation showed that the major elements present were La, $\mathrm{Re}$, and $\mathrm{O}$, which suggested that a continuous protective layer had been formed on the worn surface in the form of $\mathrm{La}\left(\mathrm{ReO}_{4}\right)_{3}$, with low shear strength at high temperature, and that the friction mainly occurred in the interior of the layer. As a result, the friction coefficients of the pair lubricated by PETE with $\mathrm{La}\left(\mathrm{ReO}_{4}\right)_{3}$ additive were remarkably lower than that lubricated by pure PETE at high temperature.

\subsection{Ionic potential analysis}

The shear susceptibility and thermal stability of the $\mathrm{La}\left(\mathrm{ReO}_{4}\right)_{3}$ composite could be explained in terms of their crystal structure. ${ }^{36}$ The double oxide $\mathrm{La}\left(\mathrm{ReO}_{4}\right)_{3}$ composite can be considered

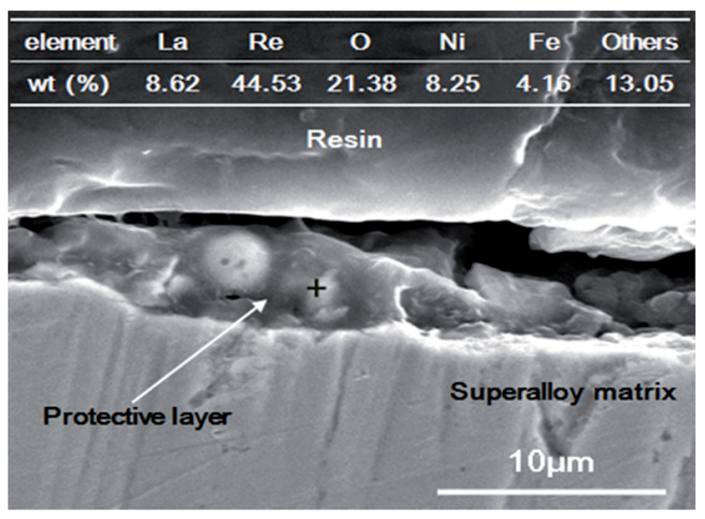

Fig. 13 Cross-section image of worn surface lubricated by PETE with $0.5 \mathrm{wt} \% \mathrm{La}\left(\mathrm{ReO}_{4}\right)_{3}$ after sliding test at $600{ }^{\circ} \mathrm{C}$ and EDS analysis of marked point. to consist of the two single oxides $\mathrm{La}_{2} \mathrm{O}_{3}$ and $\mathrm{Re}_{2} \mathrm{O}_{7}$, which possess ionic potentials of 2.9 and 12.5, respectively. Clearly, from the large difference in ionic potentials, the cations were well-separated from each other and completely shielded by the anions; hence they underwent little or no interaction with surrounding cations. Consequently, the double oxide displayed relatively low hardness and shear strength at elevated temperature. Furthermore, the ability of the ionic species to generate a stable compound was high on account of the large difference in ionic potentials, and the lower attraction between the rubbing pair led to reduced adhesive force across the rubbing contact interface. In the tested temperature scope, the $\mathrm{La}\left(\mathrm{ReO}_{4}\right)_{3}$ composite, as a solid lubricating additive, combined well with the base oil without deteriorating the lubricity and thermal stability of the oil. Moreover, it could form a highly compressive layer with the native oxides of the superalloy on the outermost surface in this elevated temperature range, enabling it to bear a substantial applied load. Thus, the $\mathrm{La}\left(\mathrm{ReO}_{4}\right)_{3}$ composite could be regarded as a promising candidate for a lubricating oil additive for specific applications across a range of temperatures.

\section{Conclusions}

In this paper, the $\mathrm{La}\left(\mathrm{ReO}_{4}\right)_{3}$ composite was successfully synthesized via the aqueous solution method and a solid/liquid hybrid lubrication mixture was prepared by an advanced dispersion technique. The tribological properties of the base oil with or without a certain concentration of $\mathrm{La}\left(\mathrm{ReO}_{4}\right)_{3}$ under the four-ball test and ball-on-disc sliding friction test across a wide temperature range were studied. The major conclusions can be summarized as follows:

1. The extreme pressure properties and lubrication performance, relative to the pure base oil, were improved to various degrees depending on the concentration of the $\mathrm{La}\left(\mathrm{ReO}_{4}\right)_{3}$ composite as a lubricating additive in the base oil under fourball test conditions.

2. The friction test results for a wide temperature range showed that the presence of the $\mathrm{La}\left(\mathrm{ReO}_{4}\right)_{3}$ composite as an oil additive powerfully improved the friction-reducing and antiwear performances at high temperatures compared with base oil alone. Meanwhile, the addition of $\mathrm{La}\left(\mathrm{ReO}_{4}\right)_{3}$ did not affect the excellent oil-lubrication properties at relatively low temperatures.

3. The formation of a protective layer containing the $\mathrm{La}\left(\mathrm{ReO}_{4}\right)_{3}$ composite and native oxides of the matrix on the counterface played an important role in the friction reduction during the friction test at high temperature. The $\mathrm{La}\left(\mathrm{ReO}_{4}\right)_{3}$ composite possessed intrinsic shear susceptibility and thermal stability by virtue of the large ionic potential difference, which prevented the direct contact between the rubbing pair and reduced the friction force. The experimental results revealed the huge potential for using oil containing the $\mathrm{La}\left(\mathrm{ReO}_{4}\right)_{3}$ composite as a hybrid mode to achieve lubricating applications in a wide range of temperatures. 


\section{Acknowledgements}

The authors are grateful to the National Natural Science Foundation of China (51175489), the Natural Science Foundation of Liaoning Province (20170540740), the Tribology Science Fund of State Key Laboratory of Tribology (SKLTKF16B07), and the Science Fund of SJZU (2017051) for financial support.

\section{References}

1 S. H. Wan, A. K. Tieu, Y. N. Xia, H. T. Zhu, B. H. Tran and S. G. Cui, An overview of inorganic polymer as potential lubricant additive for high temperature tribology, Tribol. Int., 2016, 102, 620-635.

2 H. Spikes, Tribology research in the twenty-first century, Tribol. Int., 2001, 34, 789-799.

3 T. W. Scharf, S. V. Prasad, P. G. Kotula, J. R. Michael and C. V. Robino, Elevated temperature tribology of cobalt and tantalum-based alloys, Wear, 2015, 330-331, 199-208.

$4 \mathrm{H}$. E. Sliney, Solid lubricant materials for high temperaturesa review, Tribol. Int., 1982, 15, 303-315.

5 E. Y. Liu, W. Z. Wang, Y. M. Gao and J. H. Jia, Tribological propertis of adaptive Ni-based composites with addition of lubricious $\mathrm{Ag}_{2} \mathrm{MoO}_{4}$ at elevated temperatures, Tribol. Lett., 2012, 47, 21-30.

6 M. Y. Niu, Q. L. Bi, S. Y. Zhu, J. Yang and W. M. Liu, Microstructure, phase transition and tribological performances of $\mathrm{Ni}_{3} \mathrm{Si}$-based self-lubricating composite coatings, J. Alloys Compd., 2013, 555, 367-374.

7 L. Q. Kong, Q. L. Bi, M. Y. Niu, S. Y. Zhu, J. Yang and W. N. Liu, $\mathrm{ZrO}_{2}\left(\mathrm{Y}_{2} \mathrm{O}_{3}\right)-\mathrm{MoS}_{2}-\mathrm{CaF}_{2}$ self-lubricating composite coupled with different ceramics from $20{ }^{\circ} \mathrm{C}$ to $1000{ }^{\circ} \mathrm{C}$, Tribol. Int., 2013, 64, 53-62.

8 E. Y. Liu, W. Z. Wan, Y. M. Gao and J. H. Jia, Tribological properties of Ni-based self-lubricating composites with addition of silver and molybdenum disulfide, Tribol. Int., 2013, 57, 235-241.

9 W. Y. Zhang, D. Demydov, M. P. Jahan, K. Mistry and A. Erdermir, Fundamental understanding of the tribological and thermal behavior of $\mathrm{Ag}-\mathrm{MoS}_{2}$ nanoparticlebased multi-component lubricating system, Wear, 2012, 288, 9-16.

10 G. J. Cui, J. R. Han and G. X. Wu, High-temperature wear behavior of self-lubricating Co matrix alloys prepared by $\mathrm{P} /$ M, Wear, 2016, 346-347, 116-123.

11 J. Chen, Y. L. An, J. Yang, X. Q. Zhao, F. Y. Yan, H. D. Zhou and J. M. Chen, Tribological properties of adaptive NiCrAlY-Ag-Mo coatings prepared by atmospheric plasma spraying, Surf. Coat. Technol., 2013, 235, 521-528.

12 S. M. Aouadi, Y. Paudel, W. J. Simonson, Q. Ge, P. Kohli, C. Muratore and A. A. Voevodin, Tribological investigation of adaptive $\mathrm{Mo}_{2} \mathrm{~N} / \mathrm{MoS}_{2} / \mathrm{Ag}$ coatings with high sulfur content, Surf. Coat. Technol., 2009, 203, 1304-1309.

13 L. Z. Du, C. B. Huang, W. G. Zhang, T. G. Li and W. Liu, Preparation and wear performance of $\mathrm{NiCr} / \mathrm{Cr}_{3} \mathrm{C}_{2}-\mathrm{NiCr} / \mathrm{hBN}$ plasma sprayed composite coating, Surf. Coat. Technol., 2011, 205, 3722-3728.
14 A. V. Bondarev, P. V. Kiryukhantsev-Korneev, D. A. Sidorenko and D. V. Shtansky, A new insight into hard low friction MoCN-Ag coatings intended for applications in wide temperature range, Mater. Des., 2016, 93, 61-72.

15 D. Stone, J. Liu, D. P. Singh, C. Muratore, A. A. Voevodin, S. Mishra, C. Muratore, Q. Ge and S. M. Aouadi, Layered atomic structures of double oxides for low shear strength at high temperatures, Scr. Mater., 2010, 62, 735-738.

16 X. W. Qi, Z. N. Jia, Y. L. Yang and B. L. Fan, Characterization and auto-restoration mechanism of nanoscale serpentine powder as lubricating oil additive under high temperature, Tribol. Int., 2011, 44, 805-810.

17 E. Fleischmann, M. K. Miller, E. Affeldt and U. Glatzel, Quantitative experimental determination of the solid solution hardening potential of rhenium, tungsten and molybdenum in single-crystal nickel-based superalloys, Acta Mater., 2015, 87, 350-356.

18 L. Huang, X. F. Sun, H. R. Guan and Z. Q. Hu, Effect of rhenium addition on isothermal oxidation behavior of single-crystal Ni-based superalloy, Surf. Coat. Technol., 2006, 200, 6863-6870.

19 Z. F. Cao, H. Zhong and Z. H. Qiu, Solvent extraction of rhenium from molybdenum in alkaline solution, Hydrometallurgy, 2009, 97, 153-157.

20 J. K. Qin, W. Z. Shao, Y. Li, C. Y. Cheng, D. D. Ren, X. G. Song and L. Zhen, Van der waals epitaxy of large-area continuous $\mathrm{ReS}_{2}$ films on mica substrate, RSC Adv., 2017, 7, 2418824194.

21 J. Rohacova and O. Ishitani, Rhenium(I) trinuclear rings as highly efficient redox photosensitizers for photocatalytic $\mathrm{CO}_{2}$ reduction, Chem. Sci., 2016, 7, 6728-6739.

22 R. C. Sun, T. Wang, S. W. Zhang, X. D. Chu and B. L. Zhu, Synthesis, structures and catalytic of cyclometalated rhenium complexes, RSC Adv., 2017, 7, 17063-17070.

23 M. Murai, T. Omura, Y. Kuninobu and K. Takai, Rheniumcatalysed dehydrogenative borylation of primary and secondary $\mathrm{C}\left(\mathrm{sp}^{3}\right)-\mathrm{H}$ bonds adjacent to a nitrogen atom, Chem. Commun., 2015, 22, 4583-4586.

24 X. X. Jiang, S. Z. Li, M. B. Peterson and S. J. Calabrese, On self-lubricating behavior of Co-Cu-Re alloys at elevated temperature, Mater. Sci. Prog., 1989, 3, 487-493.

25 S. Z. Li, X. X. Jiang, M. B. Peterson and S. J. Calabrese, Fundamental of lubrication with oxide film of Ni-Cu-Re at elevated temperature, Mater. Sci. Prog., 1990, 4, 1-7.

26 I. M. Allam, Solid lubricants for applications at elevated temperatures-a review, J. Mater. Sci., 1991, 26, 3977-3984.

27 D. S. Xiong and S. Z. Li, Lubrication behaviour of iron rhenate in relation to matching pairs at elevated temperatures, Lubr. Sci., 1999, 11, 197-205.

28 M. B. Perterson, S. J. Calabrese, S. Z. Li and X. X. Jiang, Friction of alloys at high temperature, J. Mater. Sci. Technol., 1994, 10, 313-320.

29 Y. L. Jia, H. Q. Wan, L. Chen, H. D. Zhou and J. M. Chen, Effects of nano- $\mathrm{LaF}_{3}$ on the friction and wear behaviors of PTFE-based bonded solid lubricating coatings under different lubrication conditions, Appl. Surf. Sci., 2016, 382, 73-79. 
30 J. F. Zhou, Z. S. Wu, Z. J. Zhang, W. M. Liu and H. X. Dang, Study on an antiwear and extreme pressure additive of surface coated $\mathrm{LaF}_{3}$ nanoparticles in liquid paraffin, Wear, 2001, 249, 333-337.

31 F. Y. Zhao, Z. M. Bai, Y. Fu, D. Zhao and C. M. Yan, Tribological properties of serpentine, $\mathrm{La}(\mathrm{OH})_{3}$ and their composite particles as lubricant additives, Wear, 2012, 288, $72-77$.

32 Z. F. Zhang, W. M. Liu and Q. J. Xue, Study on lubricating mechanisms of $\mathrm{La}(\mathrm{OH})_{3}$ nanocluster modified by compound containing nitrogen in liquid paraffin, Wear, 1998, 218, 139-144.

33 F. J. Jin, G. B. Yang, Y. Peng, S. M. Zhang, L. Yu and P. Y. Zhang, Preparation of borate ester and evaluation of its tribological properties as an additive in different base oils, Lubr. Sci., 2016, 28, 505-519.

34 L. L. Zhu, X. H. Wu, G. Q. Zhao and X. B. Wang, Effect of a new phosphate compound (BAFDP) addition on the lubricating performance of engine oils at elevated temperatures, Tribol. Int., 2016, 104, 383-391.

35 Y. Yang, C. H. Zhang, Y. Wang, Y. J. Dai and J. B. Luo, Friction and wear performance of titanium alloy against tungsten carbide lubricated with phosphate ester, Tribol. Int. , 2016, 95, 27-34.

36 A. Erdemir, A crystal-chemical approach to lubrication by solid oxides, Tribol. Lett., 2000, 8, 97-102. 